\title{
HUBUNGAN TINGKAT PENGETAHUAN, SIKAP DAN POLA MAKAN DENGAN KADAR GULA DARAH PADA PENDERITA DIABETES MELLITUS DI WILAYAH KERJA PUSKESMAS SUDIANG KOTA MAKASSAR
} \author{
The Working Centers Sudiang City Of Makassar \\ Muhasidah', Ruslan Hasani², Indirawaty ${ }^{3}$, Nur Wulan Majid ${ }^{4}$ \\ Poltekkes Kemenkes Makassar \\ Program Studi D.IV Keperawatan \\ Email : Nurwulanmid16@gmail.com \\ No. Telp : 082333399441
}

The Level Of Knowledge, Attitude And Eating Pattern With Blood Sugar Levels In Patients With Diabetes Mellitus In

\begin{abstract}
Diabetes Mellitus is a metabolic disorder disease caused by the pancreas is unable to produce enough insulin or the body can not use effectively produced insulin. One of the problems in the prevention of DM is the low level of knowledge, in this case the level of knowledge will affect the attitude in changing one's behavior. Improper diet causes an increase in blood sugar levels, for that one effort that can be done is to improve diet by applying the principle is the correct schedule, quantity and type of food. The purpose of this study is to analyze the relationship level knowledge, attitude and eating patterns with blood sugar levels in people with Diabetes Mellitus In the Working Area Health Center Sudiang Makassar. Research Method: This type of research is a quantitative analytical research with cross sectional design. Population and sample in this research is DM sufferer as many as 142 with purposive sampling sampling technique. The data were collected using questionnaires and measured blood sugar levels during DM patients. Data analysis using Chi Square with significance level $\alpha=0,05$. The results of research for knowledge level of $51,7 \%$ and knowledge less equal to $47,6 \%$, for good attitude equal to $51,0 \%$ and less $55,9 \%$, and result of good diet equal to $51,7 \%$ and bad $47.5 \%$. From the statistic test results can be concluded that there is a significant relationship between the level of knowledge with blood sugar levels ( $p$ value 0.000), and there is a significant relationship between attitudes with blood sugar levels ( $p$ value 0,000), and also there is a relationship significant between diet with blood sugar level ( $p$ value 0,000).
\end{abstract}

Keywords: Knowledge, Attitude, Diet, Blood Sugar Level.

\section{ABSTRAK}

Diabetes Melitus merupakan penyakit gangguan metabolik akibat pankreas tidak mampu memproduksi cukup insulin atau tubuh tidak dapat menggunakan insulin yang diproduksi secara efektif. Salah satu yang menjadi masalah pada penanggulangan DM yaitu rendahnya tingkat pengetahuan, dalam hal ini tingkat pengetahuan akan mempengaruhi sikap dalam mengubah perilaku seseorang, khusunya pada pemilihan atau penerapan pola makan yang tidak tepat dapat menyebabkan peningkatan kadar gula dalam darah, untuk itu salah satu upaya yang dapat dilakukan yaitu dengan memperbaiki pola makan dengan menerapkan prinsip 3J yaitu benar jadwal, jumlah dan jenis makanan agar kadar gula darah dapat terkontrol. Tujuan Penelitian ini yaitu untuk menganalisis hubungan tingkat pengetahuan, sikap dan pola makan dengan kadar gula darah pada penderita Diabetes Mellitus Di Wilayah Kerja Puskesmas Sudiang Kota Makassar. Metode Penelitian: Jenis penelitian ini merupakan penelitian analitik kuantitatif dengan desain cross sectional. Populasi dan sampel dalam penelitian ini yaitu penderita DM sebanyak 142 dengan tehnik pengambilan sampel purposive sampling. Pengumpulan data dilakukan dengan menggunakan kuesioner dan mengukur kadar gula darah sewaktu pasien DM. Analisis data menggunakan Chi Square dengan tingkat kemaknaan $a=0,05$. Hasil: uji statistic dapat disimpulkan bahwa terdapat hubungan yang signifikan antara tingkat pengetahuan dengan kadar gula darah (pvalue 0,000 ), dan terdapat hubungan hbungan yang signifikan antara sikap dengan kadar gula darah ( $p$ value 0,000 ), dan juga terdapat hubungan yang signifikan antara pola makan dengan kadar gula darah (pvalue 0,000).

Kata Kunci : Pengetahuan, Sikap, Pola Makan, Kadar Gula Darah. PENDAHULUAN

Diabetes Melitus merupakan penyakit gangguan metabolik akibat pankreas tidak mampu memproduksi cukup insulin atau tubuh tidak dapat menggunakan insulin yang diproduksi secara efektif.
Insulin adalah hormon yang mengatur kadar glukosa darah. Akibatnya terjadi peningkatan konsentrasi glukosa di dalam darah (Depkes, 2014).

Dari data Organisasi Kesehatan Dunia (2016) jumlah penderita diabetes mellitus terbanyak 
diperkirakan berada di wilayah Asia Tenggara dan Pasifik bagian Selatan mencakup sekitar setengah kasus diabetes mellitus di dunia yang dimana telah mencapai 422 juta jiwa pada tahun 2014. Jumlah penderita diabetes terus meningkat dari tahun 1980 sampai pada tahun 2014 dan peningkatannya jauh lebih tinggi dari 108 juta jiwa menjadi 422 juta jiwa (WHO, 2016).

Secara global jumlah penderita diabetes melitus dari tahun ke tahun terus meningkat yang dimana Indonesia sendiri termasuk salah satu negara berkembang di dunia bagian Asia Tenggara yang menempati peringkat ke 6 di dunia. Internasional Diabetes Federation (2015) menyatakan bahwa terdapat 415 juta orang yang hidup dengan diabetes melitus dan pada tahun 2040 jumlah tersebut diperkirakan akan mengalami peningkatan menjadi 642 juta orang. Adapun estimasi terakhir dari International Diabetes Federation (2017) terdapat 425 juta orang yang berusia 20-79 tahun yang hidup dengan diabetes melitus, pada tahun 2045 jumlah tersebut diperkirakan akan meningkat menjadi 629 juta orang. Berdasarkan data-data yang ada, penyakit diabetes melitus mengalami peningkatan dimana pada tahun 2015 hanya terdapat 415 juta orang dan meningkat pada tahun 2017 sebesar 425 juta orang (IDF, 2017).

Berdasarkan hasil data Riset Kesehatan Dasar (2013) prevalensi penderita diabetes mellitus di Sulawesi Selatan yang terdiagnosis dokter sebesar $(1,6 \%)$ dan berdasarkan gejala sebesar $(5,4 \%)$. Prevalensi Diabetes Melitus yang didiagnosis dokter tertinggi terdapat di Kabupaten Pinrang (2,8\%), Kota Makassar (2,5\%), Kabupaten Toraja Utara (2,3\%) dan Kota Palopo (2,1\%). Prevalensi Diabetes Melitus yang didiagnosis dokter atau berdasarkan gejala tertinggi di Kabupaten Tana Toraja (6,1\%), Kota Makassar (5,3\%), Kabupaten Luwu (5,2\%) (Kemenkes, 2013).

Salah satu yang menjadi masalah pada penanggulangan diabetes mellitus yaitu rendahnya tingkat pengetahuan, dalam hal ini tingkat pengetahuan akan mempengaruhi pola makan

yang dapat menyebabkan peningkatan kadar gula dalam darah, untuk itu salah satu upaya yang dapat dilakukan yaitu dengan memperbaiki pola makan melalui pemilihan makanan yang tepat. Hasil penelitian menunjukkan tingkat pengetahuan tentang kepatuhan diit DM masih sangat beragam yang dimana pasien memiliki pengetahuan tentang diabetes mellitus yang tidak lengkap (Insiyah dan Hastuti, 2016)

Menurut hasil penelitian Perdana dkk (2015) mengemukakan bahwa pengetahuan pasien tentang DM merupakan sarana yang dapat membantu penderita menjalankan penanganan diabetes sehingga semakin banyak dan semakin baik pasien
DM mengetahui tentang diabetes mellitus serta mengubah perilakunya, akan dapat mengendalikan kondisi penyakitnya sehingga ia dapat hidup lebih lama dengan kualitas hidup yang baik. Hasil penelitian ini menunjukkan terdapat hubungan yang bermakna antara tingkat pengetahuan dengan pengendalian kadar glukosa darah. Hal ini berarti bahwa kelompok responden dengan pengetahuan baik, kadar glukosa darahnya cenderung lebih terkendali dibanding dengan kelompok responden yang memiliki tingkat pengetahuan kurang (Perdana dkk, 2015).

Sikap penderita dipengaruhi oleh pengetahuan, dalam hal ini pengetahuan penderita tentang penyakit DM sangat penting karena pengetahuan akan membawa penderita DM untuk menentukan sikap, berfikir dan berusaha untuk mengelola penyakitnya serta mengontrol gula darah (Dwi Vinti, 2015).

\section{METODE}

\section{Desain, tempat dan waktu}

Jenis penelitian ini bersifat analisis kuantitatif dengan menggunakan desain cross sectional. Rancangan penelitian ini yaitu dengan menggunakan kuesioner dan mengukur kadar gula darah sewaktu pasien DM yang berada di wilayah kerja Puskesmas Sudiang Raya Kecamatan Biringkanaya Kota Makassar.

Jumlah dan cara pengambilan subjek atau bahan dan alat

Populasi dalam penelitian ini adalah seluruh pasien DM yang berkunjung di wilayah kerja Puskesmas Sudiang dan Puskesmas Sudiang Raya Kecamatan Biringkanaya Kota Makassar dengan total populasi 1 tahun terakhir yaitu 220 orang, dengan besar sampel yang didapatkan dalam penelitian ini adalah 142 orang. Teknik pengambilan sampel dalam penelitian ini yaitu dengan teknik purposive sampling.

Instrumen penelitian ini menggunakan lembar observasi dan kuesioner.

Analisa data menggunakan analisis univariat dan analisis bivariat. Analisis bivariat melalui uji statistik yaitu dengan menggunakan uji chi square.

\section{HASIL DAN PEMBAHASAN}

\section{Gambaran Umum Responden}

Tabel 4.1

Distribusi Frekuensi Responden Menurut Usia Pada Penderita Diabetes Mellitus

\begin{tabular}{ccc}
\hline Kategori Umur & \multicolumn{2}{c}{ Jumlah } \\
\cline { 2 - 3 } & $\mathrm{f}$ & $\%$ \\
\hline $31-40$ tahun & 1 & $0,7 \%$ \\
\hline $41-50$ tahun & 12 & $8.4 \%$ \\
\hline $51-60$ tahun & 66 & $46,2 \%$ \\
\hline
\end{tabular}




\begin{tabular}{ccc}
\hline $61-70$ tahun & 63 & $44,1 \%$ \\
\hline Total & 142 & $100 \%$ \\
\hline
\end{tabular}

Sumber : Data Primer 2018

Berdasarkan table 4.1 dapat diketahui bahwa penderita diabetes mellitus di Wilayah Kerja Sudiang Kec. Biringkanaya Kota Makassar rata-rata berusia $51-60$ tahun 66 orang $(46,2 \%)$, yang berusia $61-70$ tahun masing-masing 63 orang $(44,1 \%)$, sedangkan yang berusia $41-50$ tahun 12 orang $(8,4 \%)$, dan yang berusia 31-40 tahun 1 orang $(0,7 \%)$.

Rata-rata usia responden ini sesuai dengan teori yang menyebutkan bahwa usia lebih dari 40 tahun merupakan salah satu faktor risiko terjadinya penyakit Diabetes Melitus (Nuari, 2017), hal ini dikarenakan adanya perubahan anatomis, fisiologis dan biokimia. Perubahan dimulai dari tingkat sel, kemudian berlanjut pada tingkat jaringan dan akhirnya pada tingkat organ yang dapat mempengaruhi homeostasis (Damayanti S, 2015).

Tabel 4.2

Distribusi Frekuensi Responden Menurut Jenis Kelamin Pada Penderita Diabetes Mellitus

\begin{tabular}{ccc}
\hline $\begin{array}{c}\text { Kategori Jenis } \\
\text { Kelamin }\end{array}$ & \multicolumn{2}{c}{ Jumlah } \\
\cline { 2 - 3 } & $\mathrm{f}$ & $\%$ \\
\hline Perempuan & 92 & $35,0 \%$ \\
\hline Laki-laki & 50 & $64,3 \%$ \\
\hline Total & 142 & $100 \%$
\end{tabular}

Sumber : Data primer 2018

Berdasarkan tabel 4.2 dapat diketahui bahwa penderita diabetes mellitus di wilayah kerja Puskesmas Sudiang Kec. Biringkanaya Kota Makassar sebagian besar berjenis kelamin perempuan sebanyak 92 orang $(64,3 \%)$, dan sebagian kecil berjenis kelamin laki-laki sebanyak 50 orang $(35,0 \%)$.

Hasil penelitian ini juga didukung oleh penelitian yang pernah dilakukan oleh Witriyani tahun 2015 tentang efektifitas senam DM dalam menurunkan kadar gula darah, dimana jumlah penderita Diabetes Melitus Tipe 2 didominasi oleh perempuan. Ini sesuai dengan teori yang menyatakan kejadian Diabetes Melitus Tipe 2 lebih tinggi pada perempuan dibandingkan pada laki-laki (Corwin, 2009). Ini dikarenakan perempuan lebih mudah mengalami kegemukan, khususnya kegemukan viseral (lemak abdomen) yang dapat menimbulkan risiko terkena Diabetes Melitus Tipe 2, selain itu perempuan juga dapat memiliki riwayat DM gestasional dan melahirkan bayi dengan berat badan lebih dari 4,5 kg (LeMone Priscilla, 2012).
Tabel 4.3

Distribusi Frekuensi Responden Menurut Pendidikan Pada Penderita Diabetes Mellitus Kategori Pendidikan Jumlah

\begin{tabular}{|c|c|c|}
\hline & $F$ & $\%$ \\
\hline SD & 17 & $11,9 \%$ \\
\hline SMP & 31 & $21,7 \%$ \\
\hline SMA & 69 & $48,3 \%$ \\
\hline Perguruan Tinggi & 25 & $17,5 \%$ \\
\hline Total & 142 & $100 \%$ \\
\hline
\end{tabular}

Sumber : Data primer 2018

Berdasarkan tabel 4.3 dapat diketahui bahwa penderita diabetes mellitus di Wilayah Kerja Puskesmas Sudiang Kec. Biringkanaya Kota Makassar untuk tingkat pendidikan yaitu lulusan SD sebanyak 17 orang $(11,9 \%)$, lulusan SMP yaitu 31 orang $(21,7 \%)$, lulusan SMA sebanyak 69 orang $(48,3 \%)$, dan lulusan perguruan tinggi 25 orang $(17,5 \%)$.

Tingkat pendidikan dapat mempengaruhi kemampuan, pengetahuan, dan perilaku seseorang dalam menerapkan gaya hidup sehat, terutama dalam upaya pengendalian kadar glukosa darah (Anggelin dkk, 2016).

Tabel 4.4

Distribusi Frekuensi Responden Menurut PekerjaanPada Penderita Diabetes Mellitus

Kategori Jumlah

Pekerjaan

\begin{tabular}{ccc}
\hline PNS & 19 & $13,3 \%$ \\
\hline Wiraswasta & 45 & $31,5 \%$ \\
\hline Pensiunan & 8 & $5,6 \%$ \\
\hline IRT & 70 & $49,3 \%$ \\
\hline Total & 142 & $100 \%$
\end{tabular}

Sumber : Data primer 2018

Berdasarkan tabel 4.4 dapat diketahui bahwa penderita diabetes mellitus di Wilayah Kerja Puskesmas Sudiang Kec. Biringkanaya Kota Makassar untuk rerata pekerjaan yaitu PNS sebanyak 19 orang $(13,3 \%)$, Wiraswasta yaitu 45 orang $(31,5 \%)$, Pensiunan sebanyak 8 orang $(5,6 \%)$, dan IRT sebanyak 70 orang $(49,3 \%)$.

Dari hasil penelitian didapatkan jenis kelamin perempuan lebih dominan dibandingkan laki-laki. Ini sesuai dengan teori yang menyatakan kejadian Diabetes Melitus lebih tinggi pada perempuan dibandingkan pada laki-laki (Corwin, 2009). 
Tabel 4.5

Distribusi Frekuensi Responden Menurut Riwayat Keluarga DM Pada Penderita Diabetes Melittus

\begin{tabular}{ccc}
\hline \multirow{2}{*}{$\begin{array}{c}\text { Kategori Riwayat } \\
\text { DM }\end{array}$} & \multicolumn{2}{c}{ Jumlah } \\
\cline { 2 - 3 } & $\mathrm{f}$ & $\%$ \\
\hline Ada & 48 & $33,6 \%$ \\
\hline Tidak Ada & 94 & $65,7 \%$ \\
\hline Total & 142 & $100 \%$ \\
\hline
\end{tabular}

Sumber: Data primer 2018

Berdasarkan tabel 4.5 dapat diketahui bahwa penderita diabetes mellitus di Wilayah Kerja Puskesmas Sudiang Kec. Biringkanaya Kota Makassar sebagian besar tidak memiliki riwayat DM yaitu sebanyak 94 orang $(64,3 \%)$, dan sebagian kecil memiliki riwayat DM yaitu sebanyak 48 orang $(35,0 \%)$.

Genetik ataupun faktor keturunan merupakan salah satu faktor risiko terjadinya Diabetes Melitus dan memiliki peluang menderita Diabetes Melitus sebesar $15 \%$ dan juga berisiko mengalami intoleransi glukosa yaitu ketidakmampuan dalam metabolisme karbohidrat secara normal (Damayanti S, 2015).

\section{Analisis Univariate}

a. Tingkat Pengetahuan

Tabel 4.6

Distribusi Frekuensi Responden Menurut Sikap

Penderita Diabetes Mellitus

\begin{tabular}{ccc}
\hline \multirow{2}{*}{$\begin{array}{c}\text { Kategori Tingkat } \\
\text { Pengetahuan }\end{array}$} & \multicolumn{2}{c}{ Jumlah } \\
\cline { 2 - 3 } & $\mathrm{f}$ & $\%$ \\
\hline Baik & 74 & $51,7 \%$ \\
\hline Kurang & 68 & $47,6 \%$ \\
\hline Total & 142 & $100 \%$ \\
\hline
\end{tabular}

Sumber: Data Primer

Berdasarkan tabel 4.6 dapat diketahui bahwa penderita diabetes mellitus di wilayah kerja Puskesmas Sudiang Kec. Biringkanaya Kota Makassar untuk tingkat pengetahuan yang baik yaitu 74 orang $(51,7 \%)$, dan yang memiliki pengetahuan kurang yaitu 68 orang $(47,6 \%)$.

Hal ini sejalan dengan hasil penelitian Perdana dkk (2015) dimana terdapat hubungan yang bermakna antara tingkat pengetahuan dengan pengendalian kadar glukosa darah, ia juga mengemukankan bahwa pengetahuan pasien tentang DM merupakan sarana yang dapat membantu penderita menjalankan penanganan diabetes sehingga semakin banyak dan semakin baik pasien DM mengetahui tentang diabetes mellitus serta mengubah perilakunya, akan dapat mengendalikan kondisi penyakitnya sehingga ia dapat hidup lebih lama dengan kualitas hidup yang baik.

b. Sikap

Tabel 4.7

Distribusi Frekuensi Responden Menurut Tingkat Pengetahuan Pada Penderita Diabetes Mellitus

\begin{tabular}{ccc}
\hline Kategori & \multicolumn{2}{c}{ Jumlah } \\
\cline { 2 - 3 } Sikap & $\mathrm{f}$ & $\%$ \\
\hline Baik & 73 & $51,0 \%$ \\
\hline Buruk & 69 & $48,6 \%$ \\
\hline Total & 142 & $100 \%$ \\
\hline
\end{tabular}

Sumber: Data Primer.

Berdasarkan tabel 4.7 dapat diketahui bahwa penderita diabetes mellitus di wilayah kerja Puskesmas Sudiang Kec. Biringkanaya Kota Makassar untuk sikap yang baik yaitu 73 orang $(51,0 \%)$, dan yang memiliki sikap buruk yaitu 69 orang $(48,6 \%)$.

c. Pola Makan

Tabel 4.8

Distribusi Frekuensi Responden Menurut Pola Makan Pada Penderita Diabetes Mellitus

\begin{tabular}{ccc}
\hline $\begin{array}{c}\text { Kategori Pola } \\
\text { Makan }\end{array}$ & \multicolumn{2}{c}{ Jumlah } \\
\cline { 2 - 3 } & $\mathrm{f}$ & $\%$ \\
\hline Baik & 80 & $55,9 \%$ \\
\hline Buruk & 62 & $48,3 \%$ \\
\hline Total & 142 & $100 \%$
\end{tabular}

Sumber : Data primer

Berdasarkan tabel 4.8 dapat diketahui bahwa penderita diabetes mellitus di wilayah kerja Puskesmas Sudiang Kec. Biringkanaya Kota Makassar untuk pola makan yang baik yaitu 80 orang $(55,9 \%)$, dan yang memiliki pola makan yang buruk yaitu 62 orang $(48,3 \%)$.

d. Kadar Gula Darah

Tabel 4.9

Distribusi Frekuensi Responden Menurut Kadar Gula Darah Pada Penderita Diabetes Melitus

\begin{tabular}{ccc}
\hline $\begin{array}{c}\text { Kategori Kadar Gula } \\
\text { Darah }\end{array}$ & \multicolumn{2}{c}{ Jumlah } \\
\cline { 2 - 3 } & $\mathrm{f}$ & $\%$ \\
\hline Terkontrol & 74 & $51,7 \%$ \\
\hline Tidak Terkontrol & 68 & $47,5 \%$ \\
\hline Total & 142 & $100 \%$ \\
\hline
\end{tabular}

Sumber : Data primer

Berdasarkan tabel 4.9 dapat diketahui bahwa penderita diabetes mellitus di wilayah kerja Puskesmas Sudiang Kec. Biringkanaya Kota Makassar untuk kadar gula darah yang terkontrol yaitu 74 orang $(51,7 \%)$, dan yang memiliki kadar gula darah yang tidak terkontrol yaitu 68 orang $(47,5 \%)$. 
Vol. 08. No.02. 2017

e-issn : 2622-0148, p-issn : 2087-0035

\section{Analisis Bivariat}

a. Tingkat pengetahuan

Tabel 4.10

Hubungan Tingkat Pengetahuan

Dengan Kadar Gula Darah Pada

Penderita Diabetes Mellitus

\begin{tabular}{ccccccc}
\hline Tingkat Pengetahuan & \multicolumn{5}{c}{ Kadar Gula Darah } & \multirow{2}{*}{ Total } \\
\cline { 2 - 6 } & \multicolumn{2}{c}{ Terkontrol } & \multicolumn{3}{c}{ Tidak Terkontrol } & \\
\hline & $\mathrm{F}$ & $\%$ & $\mathrm{f}$ & $\%$ & $\mathrm{~F}$ & $\%$ \\
\hline Baik & 56 & $75,7 \%$ & 18 & $24,3 \%$ & 74 & 100 \\
\hline Kurang & 18 & $26,5 \%$ & 50 & $73,5 \%$ & 68 & 100 \\
\hline Total & 74 & $52,1 \%$ & 68 & $47,9 \%$ & 2 & 142 \\
\hline
\end{tabular}

Sumber : Data primer $\quad p=0,000$

Berdasarkan tabel 4.10 diperoleh hasil bahwa kadar gula darah terkontrol lebih banyak $(75,7 \%)$ pada penderita diabetes mellitus dengan tingkat pengetahuan baik, dibandingkan pada penderita diabetes mellitus yang memiliki tingkat pengetahuan kurang $(26,5 \%)$.

Dari hasil penelitian ini berdasarkan uji statistic (Chi Square) diperoleh nilai $(p=0,000<\alpha=0,05)$ yang berarti terdapat hubungan yang bermakna antara tingkat pengetahuan dengan kadar gula darah pada penderita diabetes mellitus di Wilayah Kerja Puskesmas Sudiang Kota Makassar.

Hal ini sejalan dengan hasil penelitian Muhibbudin N dkk (2016) berbasis dukungan keluarga menunjukkan adanya hubungan pengetahuan dan sikap keluarga dengan terkendalinya kadar gula darah. Dalam hal ini Anggota keluarga sangat berperan dalam pemberian intervensi pada pasien DM tipe 2 dalam memberikan dukungan emosional dan psikologis, membantu mengembangkan pengetahuan, sikap dan perilaku penderita yang sehat, serta mempromosikan manajemen diabetes secara mandiri untuk mengontrol kadar gula darah.

Berbeda dengan hasil penelitian Arizona (2014), dimana penelitian yg di dapatkan menunjukkan tidak ada hubungan yang bermakna antara tingkat pengetahuan dengan kadar gula darah $(p=0,758$ > $a=0,05)$. Hal ini disebabkan karena susahnya mengendalikan kadar gula darah, yang berarti rerata

\section{b. Sikap}

penderita sulit dalam menjalankan program diet, sebagaimana yang kita ketahui diet merupakan terapi utama bagi penderita penderita diabetes mellitus untuk mengendalikan kadar gula darah.

Adanya hubungan yang bermakna antara tingkat pengetahuan dan kadar gula darah karena pengetahuan merupakan hal penting untuk terbentuknya tindakan seseorang dan rerata penderita DM yang berada diwilayah memiliki tingkat pengetahuan yang baik, hal ini karena dari beberapa responden sering berpartisipasi dalam kegiatan edukasi mengenai program diet dalam mengontrol kadar gula darah yang biasa dilakukan oleh petugas kesehatan, dari kegiatan tersebut perilaku dapat tercipta karena didasari oleh pengetahun. Tingginya kemampuan penderita untuk mengendalikan keinginan dalam melakukan penatalaksanaan Diabetes Melitus dengan teratur mempengaruhi perilaku penderita dalam mengendalikan kadar gula darah, hal ini karena pengetahuan merupakan domain yang sangat penting untuk terbentuknya perilaku seseorang. Menurut Notoadmodjo (2007) menyatakan bahwa sebelum seseorang mengadopsi perilaku baru, didalam diri orang tersebut terjadi proses berurutan. Teori adopsi perilaku tersebut terdiri dari 5 tahap yaitu awareness (kesadaran), interest (merasa tertarik), evaluation (menimbangnimbang), trial (mulai mencoba), dan adoption.

Tabel 4.11

Hubungan Sikap Dengan Kadar Gula Darah

Pada Penderita Diabetes Mellitus

\begin{tabular}{ccccccc}
\hline Sikap & \multicolumn{5}{c}{ Kadar Gula Darah } & \multirow{2}{*}{ Total } \\
\cline { 2 - 6 } & \multicolumn{2}{c}{ Terkontrol } & \multicolumn{3}{c}{ Tidak Terkontrol } & \\
\hline & $\mathrm{F}$ & $\%$ & $\mathrm{f}$ & $\%$ & $\mathrm{f}$ & $\%$ \\
\hline Baik & 59 & $80,8 \%$ & 14 & $19,2 \%$ & 73 & 100 \\
\hline Buruk & 15 & $21,7 \%$ & 54 & $78,3 \%$ & 69 & 100 \\
\hline Total & 74 & $52,1 \%$ & 68 & $47,9 \%$ & 142 & 100 \\
\hline
\end{tabular}

Sumber: Data primer $\quad p=0,000$ 
Berdasarkan tabel 11 diperoleh hasil bahwa kadar gula darah terkontrol lebih banyak $(80,8 \%)$ pada penderita diabetes mellitus dengan sikap baik, dibandingkan pada penderita diabetes mellitus yang memiliki sikap buruk $(21,7 \%)$.

Dari hasil uji statistic (Uji Chi Square) diketahui bahwa terdapat hubungan yang bermakna antara sikap dengan kadar gula darah pada penderita diabetes mellitus di Puskesmas Sudiang $(p<0,05)$.

Namun hal ini tidak sejalan dengan penelitian Ingrid S (2015) yang menyatakan tidak terdapat hubungan antara pola sikap dengan kadar glukosa darah dengan nilai $p=0,717$.

Peneliti berasumsi berdasarkan hasil penelitian yang didapatkan bahwa adanya hubungan yang bermakna antara sikap dan kadar gula darah disebabkan karena sikap merupakan asal mula dari menerima dan rerata penderita telah menerima dirinya sebagai penderita diabetis, juga mampu menanggapi penyakitnya sendiri dengan mengikut sertakan dirinya secara aktif perihal memperhatikan jadwal kunjungan / check up dan menilai suatu masalah yang terjadi dan menganggap bahwa hal itu penting untuk dirinya sendiri (Wawan dan Dewi, 2010). Beberapa faktor yang juga mendukung seperti dukungan keluarga yang baik, pengalaman serta fasilitas yang memadai juga berhubungan secara langsung dengan sikap seseorang dalam mewujudkan perilaku yang positif. Hal ini menunjukkan rerata penderita DM yang berada diwilayah kerja Sudiang memiliki sikap positif yang dimana ini akan memudahkan penderita dalam melakukan suatu tindakan.

\section{c. Pola Makan}

Tabel 4.12

Hubungan Pola Makan Dengan Kadar Gula Darah Pada Penderita Diabetes Mellitus

\begin{tabular}{ccccccc}
\hline \multirow{2}{*}{ Pola Makan } & \multicolumn{5}{c}{ Kadar Gula Darah } & \multirow{2}{*}{ Total } \\
\cline { 2 - 6 } & \multicolumn{2}{c}{ Terkontrol } & \multicolumn{3}{c}{ Tidak Terkontrol } & \\
\hline B & $\mathrm{f}$ & $\%$ & $\mathrm{~F}$ & $\%$ & $\mathrm{f}$ & $\%$ \\
\hline Buruk & 69 & $86,2 \%$ & 11 & $13,8 \%$ & 80 & 100 \\
\hline Total & 5 & $8,1 \%$ & 57 & $91,9 \%$ & 62 & 100 \\
\hline
\end{tabular}

Sumber: Data Primer $p=0,000$

Berdasarkan tabel 4.10 diperoleh hasil bahwa kadar gula darah terkontrol lebih banyak $(86,2 \%)$ pada penderita diabetes mellitus dengan pola makan baik, dibandingkan pada penderita diabetes mellitus yang memiliki pola makan buruk $(8,1 \%)$.

Dari hasil uji statistic (Uji Chi Square) diketahui bahwa terdapat hubungan yang bermakna antara pola makan dengan kadar gula darah pada penderita diabetes mellitus di Puskesmas Sudiang $(p<0,05)$.

Hal ini sejalan dengan penelitian Insyiah dan Hastuti (2016) yang mengemukakan bahwa kepatuhan terhadap diit DM adalah bagaimana responden mengikuti aturan makan yang telah dianjurkan sesuai dengan kebutuhan kalorinya yang harus dipenuhi dalam sehari, kepatuhan tersebut meliputi jumlah kalori, jenis makan dan jadwal makan.

Hasil penelitian ini juga sejalan dengan Phitri dan Widyaningsih (2014) yang dimana hasilnya menunjukkan adanya hubungan antara pengetahuan dan sikap penderita diabetes mellitus dengan kepatuhan diet diabetes mellitus di rsud am. parikesit kalimantan timur ( $p$ value $=0,015$ ). Motivasi dalam menjalankan perencanaan makan / program diet sebagian besar rendah sebanyak 21 responden $(41,2 \%)$. Kepatuhan menjalankan program diet (perencanaan makan) sebagian besar tidak patuh sebanyak 29 responden (56,9\%). Adanya hubungan antara motivasi pasien diabetes mellitus dengan kepatuhan menjalankan program diet karena minimnya informasi yang diperoleh, kurangnya kesadaran serta motivasi dalam memanajemen penyakit yang diderita oleh pasien itu sendiri.

Adanya hubungan yang bermakna antara pola makan dengan kadar gula darah karena rerata pendeita DM yang berada di wilayah kerja sudiang sering berpartisipasi dalam penyuluhan edukasi, disertai dengan pengetahuan dan sikap masyarakat yang baik dalam pemilihan makan yang tepat seperti lebih banyak mengkonsumsi sayur dan buah dibanding karbohidrat, keteraturan jadwal makan dan jumlah yang telah ditentukan, meskipun pada kenyataannya juga masih ada sebagian responden yang belum bisa melakukan / menjalankan dengan baik program diet yang dianjurkan.

\section{KESIMPULAN}

1. Ada hubungan yang bermakna antara tingkat pengetahuan dengan kadar gula darah pada penderita diabetes mellitus di wilayah kerja Puskesmas Sudiang Kota Makassar.

2. Ada hubungan yang bermakna antara sikap dengan kadar gula darah pada penderita diabetes mellitus di wilayah kerja Puskesmas Sudiang Kota Makassar. 
3. Ada hubungan yang bermakna antara pola makan dengan kadar gula darah pada penderita diabetes mellitus di wilayah kerja Puskesmas

SARAN Sudiang Kota Makassar.

1. Penderita

a. Agar dapat meningkatkan pengetahuan tentang pola makan dengan kadar gula darah.

b. Agar dapat mengubah sikap dalam mengatur pola makan dalam mengendalikan kadar gula darah.

c. Agar dapat mematuhi pola makan yang benar menurut jenis, jumlah dan jadwal yang dianjurkan oleh petugas kesehatan dan menjalankan perilaku hidup sehat dalam mengontrol kadar gula darah.

2. Puskesmas a. Perlu adanya peningkatan kerja dalam memberikan edukasi mengenai Diabetes Mellitus kepada penderita baik secara berkelompok maupun perorangan minimal 23kali dalam sebulan.

b. Adanya pengembangan pemberian informasi tentang Diabetes Mellitus seperti pemasangan baliho / spanduk di Puskesmas maupun sekitar Wilayah Kerja Puskesmas Sudiang.

3. Peneliti Lain

Diharapkan peneliti selanjutnya meneliti beberapa variabel yang belum diteliti seperti dalam tingkat pengetahuan yaitu analisis, sintesis dan evaluasi, untuk sikap yaitu mengelolah dan menghayati dan pola makan seperti makanan selingan yang tepat untuk penderita diabetes mellitus.

Arizona N (2014). Tingkat

\section{DAFTAR PUSTAKA}

Pengetahuan, Status Gizi dan Kepatuhan Terapi Diit Pasien DM Tipe 2 dengan Kadar Gula Darah di Poli Penyakit dalam RSD dr. Soebandi Jember). Dari http://repository.unej.ac.id.

A.Wawan \& Dewi M. (2010). Pengetahuan, Sikap dan Perilaku Manusia. Cetakan I. Yogyakarta: Nuha Medika

A.Wawan \& Dewi M. (2011). Teori dan Pengukuran Pengetahuan, Sikap, dan Perilaku Manusia. Cetakan II.

Yogyakarta: Nuha Medika

Damayanti. Santi. (2015). Diabetes Mellitus dan Penatalaksanaan Keperawatan. Yogyakarta: Nuha Medika

Depkes. (2014) Dari http://www.depkes.go.id

Depkes, (2015). Rencana Aksi Program Pengendalian Penyakit dan Penyehatan Lingkungan. Dari http://www.depkes.go.id

IDF. (2015). Online Version Of Diabetes Atlas Sevent Edition 2015. Dari http://www.oedg.at

IDF. (2017). Online Version Of Diabetes Atlas Sevent Edition 2015. Dari http://diabetesasia.org

Ingrid S (2015). Hubungan Sikap Dan Asupan Karbohidrat Terhadap Kadar Glukosa Darah Pada Pasien Rawat Jalan DM Tipe II Di RSUD Dr. Moewardi.

Insiyah \& Hastuti RT (2016). Tingkat Pengetahuan Dan Kepatuhan Tentang Diit Diabetes Mellitus Pada Pasien

Diabetes Mellitus Di Puskesmas Sibela Kota Surakarta. Vol. 5 No.1. Dari http://jurnal.poltekkes-solo.ac.id

Kementrian Kesesehatan RI. (2013). Hasil Riset Kesehatan Dasar 2013. Jakarta: Badan Penelitian dan

Pengembangan Kesehatan. Dari http://www.depkes.go.id

Nanang M, dkk. (2016). Hubungan Pengetahuan dan Sikap Keluarga dengan Terkendalinya Kadar Gula Darah Pada

Pasien Diabetes Mellitus Tipe 2 di RSUD Kabupaten Kediri).

Nursalam, (2016). Konsep dan Penerapan Metodelogi Penelitian IImu Keperawatan. Jakarta: Salemba Medika

Notoatmodjo, S. (2015). Metedeologi Penelitian Kesehatan . Jakarta: Roneka Cipta.

Perdana AA, dkk. (2013). Hubungan Tingkat Pengetahuan Tentang Penyakit DM dengan pengendalian Kadar Glukosa Darah Pada Pasien DM tipe II di RSU PKU Muhammadiyah Surakarta. Volume 5, No.2 Dari http://journals.ums.ac.id 
Jurnal Media Keperawatan: Politeknik Kesehatan Makasar

Vol. 08. No.02. 2017

e-issn : 2622-0148, p-issn : 2087-0035

Tarwoto, dkk (2016). Keperawatan Medikal Bedah Gangguan Sistem Endokrin. Jakarta Timur: CV Trans Info Media.

Vinti, Dwi. (2015). Hubungan Pengetahuan, Sikap Dan Kepatuhan Diet Dengan Kadar Gula Darah Pada Pasien Diabetes Melitus Di Poliklinik Khusus Penyakit Dalam Rsup Dr.M.Djamil Padang Tahun 2015. Dari http://pustaka.poltekkes-pdg.ac.id

World Health Organitation (WHO), (2016). Dari http://apps.who.int 